\title{
Financial Inclusion in Zimbabwe: Determinants, Challenges, and Opportunities
}

\author{
Florence Barugahara ${ }^{1}$ \\ ${ }^{1}$ Bindura University of Science Education, Bindura, Zimbabwe \\ Correspondence: Florence Barugahara, Bindura University of Science Education, P.bag 1020, off Trojan Road, \\ Bindura, Zimbabwe. E-mail: bategekaflorence@gmail.com
}

Received: November 10, 2020

Accepted: December 23, $2020 \quad$ Online Published: February 4, 2021

doi:10.5430/ijfr.v12n3p261

URL: https://doi.org/10.5430/ijfr.v12n3p261

\begin{abstract}
Financial inclusion is a highly topical issue for policymakers since inclusive finance is viewed as a channel of social and economic development. Therefore, this paper seeks to ascertain and examine the determinants, challenges, and opportunities for financial inclusion in Zimbabwe. The research is done by examining existing literature and estimating Logit and Probit models. This paper finds that, the major determinants of financial inclusion in Zimbabwe are; gender, age, education, income levels, employment status, the cost of financial services, account opening requirements, and level of trust in the financial system. Challenges to financial inclusion in Zimbabwe include; financial illiteracy, lack of formal identification documents, lack of trust in the financial system, fragile economy, rural poor and gender inequality, and high transaction costs of financial services. However, mobile money services such as Eco-cash, Tel-cash, and One-money have proved an opportunity for inclusive finance in Zimbabwe. Furthermore, the establishment of the women's Bank of Zimbabwe is one of the strategies to enhance inclusive finance for women in Zimbabwe. The simplified KYC requirements for low-income groups and the financial inclusion strategy commissioned by the Reserve Bank of Zimbabwe are hoped to promote financial inclusion. This paper recommended that to make finance inclusive, the government should develop policies that target marginalized groups such as the elderly, rural population, low-income earners, females, and the unemployed. The government should also develop a strong consumer protection regulatory framework, promote financial literacy, reduce the transaction cost of financial services and encourage the use of accounts with simplified KYC requirements to ease documentation needs.
\end{abstract}

Keywords: financial inclusion, Zimbabwe, economic development

\section{Introduction}

The Financial sector of Zimbabwe is made up of various players providing financial services and products. These range from development finance institutions, insurance entities, capital markets, pension funds, banks, payment systems, and microfinance institutions (Reserve Bank of Zimbabwe, 2016). As of 2015, there were 13 Commercial Banks; 1 Merchant Bank; 4 Building Societies; 1 Savings Bank; 153 Credit-only Microfinance Institutions; 2 Deposit Taking Microfinance Institutions; 2 Development Finance Institutions; 114 registered Insurance Companies; the Zimbabwe stock exchange; and many Saving and Credit Cooperatives (SACCOS) (Reserve Bank of Zimbabwe, 2016). The economic meltdown of 2000 -2009 adversely affected the banking sector in Zimbabwe with a number of commercial banks such as Trust bank, Royal bank, Timebank, and Barbican bank collapsing. Additionally, the country's adoption of the multicurrency system in 2009 resulted into a loss of depositor's funds, which eroded confidence in the Zimbabwean banking system. With little confidence in the banking system, many Zimbabweans now conduct cash transactions outside the formal channels, leading to the current liquidity shortage in the banking sector (Chitokwindo, Mago, \& Hofisi, 2014). The situation is being worsened by the current soaring inflation.

According to the Reserve Bank of Zimbabwe (Zimbabwe National financial Inclusion Strategy 2016-2020), financial inclusion refers to the sustainable cost-effective provision of a wide range of financial services at an affordable cost to the majority of the population. This enables households and micro, small and medium enterprises to engage in income-generating activities which improve their economic welfare. Ensuring the existence of an inclusive financial sector with the view of engendering social and economic development is the goal for the establishment of the National Financial Inclusion Strategy for Zimbabwe (Reserve Bank of Zimbabwe, 2016). Park 
\& Mercado (2015) concur that inclusive finance is often considered as a major factor for inclusive economic growth since access to finance allows economic agents to make longer-term consumption and investment decisions, participate in productive activities, and cope with unexpected short-term shocks.

Consonantly, Demirguc-kunt et al., (2014) argue that inclusive finance has been extensively regarded as important for poverty reduction and attaining inclusive economic growth. These authors further state that increased access to financial services for both individuals and firms may lead to a reduction in income inequality and increased economic growth. Similarly, Sharma (2016) found that banking penetration strongly impacts on economic growth. Although financial development improves resource allocation thus reducing poverty and income inequality, Barugahara (2012) finds that inflation reduces the ability of financial intermediaries to allocate resources. This is because, in an inflationary environment, credit rationing intensifies due to reduced and greater variability of returns, thus financial sectors make few loans, resource allocation becomes inefficient and intermediary activity declines with adverse implications for inequality and development. Therefore, current harsh economic conditions characterized by soaring inflation could be posing a major challenge to inclusive finance in Zimbabwe.

The financial exclusion rate in Zimbabwe reduced to 23\% in 2014 from 40\% in 2011 (Finscope Survey, 2014). Despite this reduction in the share of the financially excluded in Zimbabwe, the rate (23\%) is still high. Moreover, the Finscope Survey, (2014) also finds that adult financial inclusion is much higher among the urban population (89\%) compared to the rural population (62\%) where two thirds of Zimbabwean adults live. With the majority of the people who are financially excluded dwelling in rural areas, this could promote high levels of inequality and poverty in Zimbabwe. Given this condition, it calls for the establishment of the rural banking sector for local resource mobilization and business development. The development of the rural banking sector can develop rural businesses that are currently underdeveloped partly because of financial constraints. If finance is inclusive, rural savings and investments will be enhanced thereby developing rural businesses. Abiola ( 2015) concur that local savings are promoted by financial inclusion and this leads to productive investments in local businesses.

Furthermore, according to the world bank report (World Bank, 2012), financial inclusion in MSME was considerably low with only 14\% of MSME owners being banked. Additionally, the (Zimbabwe FinScope Consumer Survey, 2014) revealed that only $20 \%$ of the adults save formally, whereas $74 \%$ do not save due to lack of disposable income. Additionally, the survey found that $58 \%$ of the Zimbabwean adults borrow mainly through informal credit with only $13 \%$ borrowing using formal credit. It was also noted that the actual use of banking products and services decreased as shown by an increase in the proportion of dormant accounts from $4 \%$ in 2011 to $25 \%$ in 2014 (deposits) and 3\% in 2011 to $9 \%$ in 2014 (withdrawals). There was also a decline in active accounts.

Moreover, women were largely excluded from the financial sector yet according to (ZimStat 2012, cited by The Zimbabwe National Budget Statement, 2016) they form the biggest part of the Zimbabwean population. A strategy to increase women's financial inclusion was developed through the Ministry of Micro, Small, and Medium Enterprises by establishing the women's bank of Zimbabwe. It is hoped that the bank will promote women's financial inclusion and entrepreneurship. Furthermore, the youth are inappropriately affected by a high level of unemployment thus largely explaining the low levels of financial inclusion among the youth.

This paper examines the determinants of financial inclusion in Zimbabwe and highlights the challenges and opportunities for financial inclusion in the economy. Zimbabwe was selected given the fact that it is among the countries with the highest level of financial exclusion in the world besides facing harsh economic conditions. Importantly, this paper brings forth new evidence by employing the most recent available data (2017 financial inclusion data) provided by the World Bank.

\section{Literature Review}

The Reserve Bank of Zimbabwe (Zimbabwe National financial Inclusion Strategy 2016-2020), defines financial inclusion as the sustainable cost-effective provision of a wide range of financial services at an affordable cost to the majority of the population. This enables households and micro, small and medium enterprises to engage in income-generating activities which improve their economic welfare. According to Joshi (2011) the Reserve Bank of India, defines financial inclusion as the process of ensuring access to a full suite of quality financial services, provided at affordable cost, conveniently, and with dignity to the entire population without discrimination of any type particularly against vulnerable groups such as weaker and low-income groups.

Demirguc-Kunt and Klapper (2012) provided an analysis of the Global Financial Inclusion (Global Findex) Database and found that $50 \%$ of adults worldwide had an account at a formal financial institution, though account penetration varied widely across regions, income groups, and individual characteristics. Their research also found that $22 \%$ of 
adults had saved at a formal financial institution in the preceding 12 months, and 9\% had taken out a new loan from a bank, credit union, or microfinance institution in the preceding year. The authors also found that among the most commonly reported barriers of financial inclusion are high cost, physical distance, and lack of proper documentation, though there are significant differences across regions and individual characteristics. On a positive note, Demirguc-kunt and Klapper (2014) in their analysis of the Global Findex Database 2014 found that between 2011 and 2014, 700 million adults became account holders while the number of those without an account (the unbanked) dropped by $20 \%$ to 2 billion. This was attributed to a growth in account penetration of $13 \%$ in developing economies and innovations in technology (particularly mobile money) which is helping to rapidly expand access to financial services in Sub-Saharan Africa.

Despite lagging behind other regions, Africa has seen a large increase in the number of adults with accounts, from 23\% in 2011 (Demirguc-Kunt \& Klapper, 2012) to 43\% in 2017. According to the survey, this increase has been driven largely by recent innovations in mobile banking. Besides, Zins and Weill (2016) examined the determinants of financial inclusion in Africa using the World Bank's Global Findex database on 37 African countries by performing probit estimations, and found that being a man, richer, more educated, and older favoured financial inclusion with a higher influence of education and income. This study will be specific to Zimbabwe so as to identify its uniqueness in terms of the current status of financial inclusion, drivers, challenges and opportunities.

The financial exclusion rate in Zimbabwe reduced to 23\% in 2014 from 40\% in 2011 (Finscope Survey, 2014). Moreover, Munyanyi (2014) studied women's financial inclusion in Zimbabwe employing a descriptive comparison of rural and urban populaces. The author's findings revealed that women in urban areas have greater access to financial services than those in rural areas. This resonates with the findings of the (Finscope Survey, 2014) that financial inclusion is much higher among the urban population (89\%) compared to the rural population (62\%) where two thirds of Zimbabwean adults live. Also, Chitokwindo, Mago, and Hofisi (2014) found that mobile banking has become a catalyst for financial inclusion, business development, and poverty reduction in Zimbabwe. They further state that financial inclusion promotes local savings and investments thus developing rural business and reducing poverty among the marginalized groups. Additionally, Masiyandima et al., (2017) find that among the major determinants of financial inclusion in Zimbabwe are income, financial literacy and the geographical presence of financial institutions. With regard to the link between financial inclusion and livelihood indicators, the authors found that greater financial inclusion promotes access to basic income, food, health and education for households in the country.

\section{Methodology}

\subsection{Model Specification and Econometric Methodology}

Descriptive research was used to describe the determinants of financial inclusion in Zimbabwe, in addition to identifying its challenges and opportunities. Data was collected by examining existing literature and the Fin Scope Consumer Survey 2017. Quantitative data was analysed by estimating a logit and probit model. Zimbabwe was selected because it is among the countries with the highest level of financial exclusion in the world besides facing harsh economic conditions.

Following the literature (Abel et al., 2018; Asuming et al., 2019), this study used the Probit model and logit models to estimate the determinants of financial inclusion in Zimbabwe.

$$
\begin{gathered}
p(y=1 \mid x)=G\left(\beta_{0}+\beta_{1} \text { gender }+\beta_{2} \text { age }+\beta_{3} \text { age }{ }^{2}+\beta_{4} \text { education }+\beta_{5} \text { wealth }+\beta_{6}\right. \text { employment } \\
\left.+\beta_{7} \text { expense }+\beta_{8} \text { documents }+\beta_{9} \text { trust }\right)
\end{gathered}
$$

Where $y$ is the dependent variable (financial inclusion) and is equal to one when an individual is financially included and zero otherwise. Additionally, $x$ are the explanatory variables (gender, age, $a g e^{2}$, education, wealth, employment, expenses, documents, and trust), $\beta_{0}$ and $\beta_{1}, \ldots, \beta_{9}$ are the estimated parameters, and $\mathrm{G}(\cdot)$ is a cumulative distribution function (CDF), whose specific form depends on the estimator used. The probit model assumes that the residue has normal CDF whereas the logistic model - logit assumes that the residue has CDF logistics. Both models were used for comparison and robustness. According to Gujarati (2006) logit and probit models are similar in most applications, even if the estimated coefficients are not directly comparable. Therefore, the estimated marginal effects will be used in the analysis as they are directly comparable. The model is estimated using the maximum likelihood estimation. 


\subsection{Data}

All the data (financial inclusion indicators and the explanatory variables) that was used in this study was obtained from the 2017 financial inclusion survey for Zimbabwe available in the World Bank's Findex Database. This data was randomly collected from 1000 people aged 15 years and above.

The dependent variable $y$ is measured in two ways: (1) formal financial inclusion and (2) both form and informal financial inclusion). (1) $y$ equals to one for having an account at a formal financial institution or zero otherwise, (2) $y$ equals to one for having an account at a formal financial institution, mobile money account, and any other form of account and zero otherwise. Unlike (Abel et al., 2018) who only considered formal financial services, we consider also informal financial inclusion because Zimbabwe like many low-income countries is characterized by a high degree of financial dualism. Therefore to get more robust results on the determinants of financial inclusion in Zimbabwe, there is a need to consider the informal financial services as well.

The explanatory variables include gender, age, $a g e^{2}$, education, wealth, employment, expenses, documents, and trust.

- Gender is a dummy variable which equals 1 for female and 0 for male. A negative coefficient is expected since it is more difficult for women to have a bank account (Asuming et al., 2019).

- Age refers to the age of the individual. A positive coefficient is expected for this variable because the probability of being financially included increases with age. We also include age squared for which a negative coefficient is expected with the assumption that the relationship between financial inclusion and age is nonlinear i.e middle-aged individuals have a higher propensity to join the group of the financially included when compared to young and elderly individuals.

- Education takes on three dummy variables (completed primary or less; completed secondary; and completed tertiary or more) each taking on 1 if an individual falls in that category and zero otherwise. Consistent with literature financial inclusion is expected to be high for individuals with higher education hence a positive coefficient is expected.

- Wealth is a quintile represented by five dummy variables (the poorest $20 \%$; second; middle; fourth; and richest 20\%). A positive coefficient is expected in line with the literature.

- Employment indicates the employment status of the individual and it is a dummy variable assigned to 1 if an individual is in the workforce and 0 otherwise. Employed individuals are expected to be financially included hence a positive coefficient is expected.

- Expense is a dummy variable assigned 1 if an individual is financially excluded due to transaction costs of obtaining financial services and 0 otherwise. Higher transaction costs of obtaining financial services are likely to be a barrier to financial inclusion hence a negative coefficient is accepted.

- Documents is a dummy variable assigned 1 if an individual is financially excluded due to lack of documents required by financial institutions and 0 otherwise. Lack of documentation required for account opening is likely to hinder individuals from accessing financial services hence a negative coefficient is expected.

- Trust is a dummy variable assigned 1 if an individual is financially excluded due to lack of trust in financial institutions and 0 otherwise. There is a high probability that individuals who lack confidence in the financial system will be financially excluded hence a negative coefficient is expected.

\section{Results and Discussion}

\subsection{Descriptive Statistics}

Table 1 represents the descriptive statistics of the variables used in this study. From table 1, the majority of the respondents (59\%) have an account. However, only $32 \%$ of the respondents have an account with a financial institution. The sample shows the majority of the respondents $(61 \%)$ were female and the male was $39 \%$. The average age of the adult Zimbabwean population is 36.66 years indicating that the adult Zimbabwean population is youthful? For education, the majority of the respondents (67\%) had completed secondary education, $27 \%$ completed primary or less while those with tertiary or more were $6 \%$. Basing on wealth, $25 \%$ of the respondents were from the richest quintile, $21 \%$ were from the fourth quintile while $18 \%$ belonged to the middle, second and the poorest quintiles each. Regarding employment, $67 \%$ of the respondents were employed and 33\% were out of the workforce. Considering the expenses of financial services, $18 \%$ of the respondents were excluded due to expensive financial services. Basing on documents required to open up an account, $32 \%$ of the financially excluded respondents cited 
this reason. Regarding trust in financial institutions, $15 \%$ of the financially excluded respondents lacked trust in the financial institutions.

Table 1. Summary statistics

\begin{tabular}{lllll}
\hline Variable & Mean & Sd & Min & max \\
\hline Account & 0.59 & 0.49 & 0.0 & 1 \\
\hline Account at a financial institution & 0.32 & 0.46 & 0.0 & 1 \\
\hline Gender & 0.61 & 0.49 & 0.0 & 1 \\
\hline Age & 36.66 & 16.58 & 15.0 & 88 \\
\hline Completed Primary education or less & 0.27 & 0.44 & 0.0 & 1 \\
\hline Completed Secondary education & 0.67 & 0.47 & 0.0 & 1 \\
\hline Completed Tertiary education or more & 0.06 & 0.23 & 0.0 & 1 \\
\hline Poorest wealth quintile & 0.18 & 0.38 & 0.0 & 1 \\
\hline Second wealth quintile & 0.18 & 0.39 & 0.0 & 1 \\
\hline Middle wealth quintile & 0.18 & 0.38 & 0.0 & 1 \\
\hline Fourth wealth quintile & 0.21 & 0.41 & 0.0 & 1 \\
\hline Richest wealth quintile & 0.25 & 0.43 & 0.0 & 1 \\
\hline Employment status & 0.67 & 0.47 & 0.0 & 1 \\
\hline Expensive of financial services & 0.18 & 0.39 & 0.0 & 1 \\
\hline Documents & 0.32 & 0.47 & 0.0 & \\
\hline Trust in financial institutions & 0.15 & 0.36 & 0.0 & \\
\hline $\mathrm{N}$ & 1000 & & & 1 \\
\hline
\end{tabular}

\subsection{Determinants of Financial Inclusion in Zimbabwe}

Table 2 reports the results on the determinant of financial inclusion in Zimbabwe using the two indicators of financial inclusion (has an account at a financial institution and has an account). In Table 2, columns 1 and 2 report marginal effects from the probit estimation, and columns 3 and 4 present marginal effects from the logit estimation. We begin by analysing the results from the probit model.

Table 2 shows that females are $4 \%$ less likely to have a formal account compared to males. This is in line with (Asuming et al., 2019) who argues that females are less likely to engage in formal employment that requires them to have accounts than males. However, including informal financial services, gender becomes insignificant.

Table 2. Determinants of financial inclusion in Zimbabwe - probit and logit regressions

\begin{tabular}{lllll}
\hline & Probit- regression & \multicolumn{3}{l}{ Logit - Regression } \\
\hline Variables & $(1)$ & $(2)$ & $(3)$ & $(4)$ \\
& Accountfin & Account & Accountfin & Account \\
& $\mathrm{dy} / \mathrm{dx}$ & $\mathrm{dy} / \mathrm{dx}$ & $\mathrm{dy} / \mathrm{dx}$ & $\mathrm{dy} / \mathrm{dx}$ \\
\hline Gender & $-0.0433^{*}$ & -0.0169 & $-0.0422^{*}$ & -0.0136 \\
\hline \multirow{2}{*}{ Age } & $(0.0240)$ & $(0.0300)$ & $(0.0232)$ & $(0.0302)$ \\
\hline \multirow{2}{*}{ age2 } & $0.0081^{* *}$ & $0.0149^{* * *}$ & $0.0091^{* * * *}$ & $0.0145^{* * *}$ \\
\hline
\end{tabular}




\begin{tabular}{|c|c|c|c|c|}
\hline & $(0.0000)$ & $(0.0000)$ & $(0.0000)$ & $(0.0000)$ \\
\hline \multirow[t]{2}{*}{ Secondary } & $0.0753^{* *}$ & $0.1632^{* * * *}$ & $0.0723^{* *}$ & $0.1618^{* * * *}$ \\
\hline & $(0.0323)$ & $(0.0357)$ & $(0.0316)$ & $(0.0355)$ \\
\hline \multirow[t]{2}{*}{ Tertiary } & $0.2627^{* * *}$ & $0.3166^{* * *}$ & $0.2563^{* * *}$ & $0.3256^{* * *}$ \\
\hline & $(0.0573)$ & $(0.0814)$ & $(0.0611)$ & $(0.0889)$ \\
\hline \multirow[t]{2}{*}{ Second } & $0.1268^{* * *}$ & $0.1605^{* * *}$ & $0.1198^{* * *}$ & $0.1649^{* * *}$ \\
\hline & $(0.0462)$ & $(0.0473)$ & $(0.0459)$ & $(0.0480)$ \\
\hline \multirow[t]{2}{*}{ Middle } & $0.1530^{* * *}$ & $0.1280^{* * *}$ & $0.1543^{* * *}$ & $0.1298^{* * *}$ \\
\hline & $(0.0438)$ & $(0.0468)$ & $(0.0428)$ & $(0.0466)$ \\
\hline \multirow[t]{2}{*}{ Fourth } & $0.2181^{* * *}$ & $0.2028^{* * * *}$ & $0.2159^{* * *}$ & $0.2021^{* * * *}$ \\
\hline & $(0.0414)$ & $(0.0454)$ & $(0.0406)$ & $(0.0453)$ \\
\hline \multirow[t]{2}{*}{ Richest } & $0.2828^{* * *}$ & $0.2401^{* * *}$ & $0.2704^{* * *}$ & $0.2395^{* * *}$ \\
\hline & $(0.0426)$ & $(0.0459)$ & $(0.0412)$ & $(0.0459)$ \\
\hline \multirow[t]{2}{*}{ Employment } & $0.0545^{* *}$ & $0.0619^{* *}$ & $0.0559^{* *}$ & $0.0628^{* *}$ \\
\hline & $(0.0268)$ & $(0.0312)$ & $(0.0256)$ & $(0.0310)$ \\
\hline \multirow[t]{2}{*}{ Expensive } & $-0.2734^{* * *}$ & -0.0403 & $-0.2952^{* * * *}$ & -0.0394 \\
\hline & $(0.0539)$ & $(0.0390)$ & $(0.0604)$ & $(0.0389)$ \\
\hline \multirow[t]{2}{*}{ Documents } & $-0.3339^{* * *}$ & $-0.1790^{* * *}$ & $-0.3679^{* * * *}$ & $-0.1790^{* * * *}$ \\
\hline & $(0.0295)$ & $(0.0296)$ & $(0.0345)$ & $(0.0292)$ \\
\hline \multirow[t]{2}{*}{ Trust } & $-0.2251^{* * *}$ & $-0.1237^{* * * *}$ & $-0.2667^{* * *}$ & $-0.1216^{* * * *}$ \\
\hline & $(0.0458)$ & $(0.0426)$ & $(0.0474)$ & $(0.0439)$ \\
\hline $\mathrm{N}$ & 997 & 997 & 997 & 997 \\
\hline Psuedo-R2 & 0.3658 & 0.143 & 0.3766 & 0.1521 \\
\hline
\end{tabular}

Note: dy/dx refers to marginal effects from the probit and logit regressions. Figures in parentheses stand for Robust standard errors, $* * * *, * * *$ stand for statistical significance at 1 percent, 5 percent, and 10 percent levels respectively. Account is has an account, accountfin is has an account at a financial institution. Secondary is a dummy variable for completed secondary education, tertiary is a dummy variable for completed tertiary education or more. The omitted category for education is those that completed primary education or less. Second, middle, fourth, and richest are dummy variables for the wealth quintiles. The omitted category of the wealth quintile is the poorest quintile.

Regarding age, an increase in an individual's age by one year increases the probability of being financially included by $1 \%$ for both formal account and account. The marginal effect of $a g e^{2}$ is negative indicating that the elderly have a lower probability of being financially included.

The probability of being financially included increases with the education level. Individuals who completed secondary and those who completed tertiary or more education are $1 \%$ and $3 \%$ more likely to have a formal account respectively and $2 \%$ and $3 \%$ more likely to have an account respectively compared to those who only completed primary or less. The findings are similar to (Asuming et al., 2019; Efobi, Beecroft, \& Osabuohien, 2014) who found that individuals with higher education are more likely to own an account than those with lower education.

The ownership of a formal account and an account increases with wealth. All the income quintile dummies are statistically significant. Moreover, the marginal effects become significantly larger with the increase in the level of quintile. This implies that as individuals' income increases, the probability of being financially included also increases. Abel et al. (2018) report similar results. 
Regarding employment, the probability of having a formal account and an account increases by $1 \%$ in both cases and this is statistically significant at $5 \%$ level of significance. This implies being in the workforce increases the likelihood of being financially included.

Concerning expenses of financial services, the variable is only significant when it comes to having a formal account. The marginal effect is negative and statistically significant at $1 \%$ level of significance. A unit increase in the transaction cost of financial services reduces the probability of an individual having a formal account by $3 \%$. This implies that the cost of transacting through a bank is one of the main barriers for seeking formal financial services in Zimbabwe.

Lack of documents such as the national identity card, proof of residence, etc. prevents individuals from being financially included. The lack of documents is statistically significant in all the models. Lack of documents reduces the likelihood of having a formal account and an account by $3 \%$ and $2 \%$ respectively. Demirguc-Kunt \& Klapper,(2012) find similar results.

Lack of trust in the financial system hinders financial inclusion. As shown in table 2, lack of trust in the financial system reduces the probability of having a formal account and an account by $2 \%$ and $1 \%$ respectively. Demirguc-Kunt \& Klapper,(2012) concur that the lack of trust in the banking system has caused disparities in the financial systems across the world.

For comparison and robustness check the models on the determinants of financial inclusion in Zimbabwe were estimated using the logit model. The results from the logit model are also reported in Table 2 in columns 3 and 4 for formal account and account respectively. The logit model produces similar results to the probit model in terms of marginal effects and significance.

\subsection{Challenges Facing Inclusive Finance in Zimbabwe}

Financial experts generally concur that increasing access to financial services can lead to an improvement in the economic welfare of peoples' lives. However, despite the benefits of financial inclusion and the technological advancements, 23\% of Zimbabweans were financially excluded, only 30\% of Zimbabwe's adult population made use of banking services as of 2014 and only $20 \%$ of the adult population made use of formal savings channels (Zimbabwe FinScope Consumer Survey, 2014). To address this issue the country launched the National Financial Inclusion Strategy (2016-2020) with the objective to bring basic financial services to these unbanked individuals. However, there are several challenges faced by policymakers as they try to attain a higher level of inclusive finance in Zimbabwe, and these include;

Lack of awareness about the available financial services prevents Zimbabweans from utilizing the right financial products and services. Reserve Bank of Zimbabwe (2016) also notes that insufficient information on financial products and services and financial illiteracy are challenges for inclusive finance. This calls for improving financial literacy among the people so that they can make better financial decisions and choose the right products and services that are most suitable for their needs. Abel et al., (2018) found that financial literacy promotes financial inclusion. The authors argued that financially literate people can understand the merits and demerits of different financial products and services hence make well-informed decisions.

Lack of formal identification documents prevents individuals from seeking formal financial services. A proper ID and proof of residence are required before an individual can open a bank account. Reserve Bank of Zimbabwe (2016) concurs that failure to meet the minimum account opening requirements is among the key elements hindering inclusive finance in Zimbabwe. Therefore, authorities ought to simplify and streamline the procedure for getting a formal ID card to enhance access to banking services for the unbanked. To overcome this challenge, the Reserve Bank of Zimbabwe (RBZ) has introduced Know Your Customer (KYC) light accounts for low income earners in a bid to increase the banked.

Lack of trust/confidence in the financial system is hindering many Zimbabweans from being financially included. Reserve Bank of Zimbabwe (2016) lists the lack of confidence in the financial sector as one of the key constraints to inclusive finance in Zimbabwe. Despite the promotion of financial inclusion through mobile money platforms, there is a lack of confidence in these platforms among the people due to security and reliability reasons. Also, Zimbabwe's financial sector is fragile characterised by multiple bank closures. For example, more than 10 commercial banks have closed since 2004 which has eroded confidence in the financial sector. This has had negative repercussions for financial inclusion as it discourages people from seeking formal financial services. Policymakers ought to develop clear guidelines and regulations to increase customer confidence and trust and also ensure that the consumers are adequately protected and have access to key product information to allow them make informed decisions. 
Rural Poor and gender inequality are other problems for inclusive finance in Zimbabwe. The (Finscope Survey, 2014) finds that financial inclusion is much higher among the urban population (89\%) compared to the rural population $(62 \%)$ where two thirds of Zimbabwean adults live. Similar to (Asuming et al., 2019) this paper finds that females are $4 \%$ less likely to have a formal account compared to their male counterparts (see Table 2). In addition, there is a lower likelihood for women to access credit from banks. This may be mainly because of lack of collateral security and poor credit history. This implies financial inclusion policies should majorly target the women and the rural population.

Zimbabwe is a fragile economy where incomes are low and sometimes irregular and this hinders financial inclusion. Moreover, the already dire economic situation is exacerbated by soaring inflation. With this kind of economic environment, very few individuals and businesses seek financial services to save or invest and likewise, due to the high risk of default very few financial institutions are willing to loosen up on credit provision. In agreement, the Reserve Bank of Zimbabwe (2016) points out that low-income levels and irregular income streams hinder financial inclusion in Zimbabwe.

The high transaction costs of bank or mobile money financial services are also discouraging a number of Zimbabweans from uptaking formal financial services. Moreover, the interest earned on savings through financial institutions is very little usually completely eroded by transactional fees. For this reason individuals and small to medium enterprises (SMEs) avoid formal financial services. Both banks and micro-finance institutions are opportunistic with high-cost structures. Our results in table 2 confirm that expenses of financial services deter the use of formal financial services.

\subsection{Opportunities for Inclusive Finance in Zimbabwe}

Despite the challenges to financial inclusion, there opportunities for inclusive finance in Zimbabwe as discussed below.

The mobile money platform (Ecocash, OneMoney, Telecash, and Mycash) provides an opportunity for inclusive finance in Zimbabwe. Cash shortages coupled with higher cash withdraw charges in the banking sector, spurred the adoption and use of mobile money in Zimbabwe. Mobile money in Zimbabwe has extensively enhanced financial inclusion, rapidly extending financial coverage to many people who were earlier excluded. According to the Zimbabwe FinScope Consumer Survey (2014) results, $45 \%$ of the adult population use mobile money services. Of those, $65 \%$ mentioned that it was convenient, while $36 \%$ mentioned that it was cheaper compared to the Banking services. In Zimbabwe, mobile money is used especially for sending and receiving remittances. However, the saving and loan aspect of mobile money is not common.

The Zimbabwe Women Microfinance Bank Limited is another opportunity for promoting inclusive finance in the marginalized groups particularly the women. It is a deposit-taking microfinance institution in Zimbabwe that serves those members of the community who have been un-reached by conventional commercial banks, particularly rural women. Although the bank serves customers regardless of gender, it aims at providing services to women especially those in rural areas, with the focus on the previously unbanked. The bank provides services such as savings accounts with low opening deposits, group accounts, availability in rural areas, lending to micro, small and medium enterprises, and provision of financial literacy classes.

The simplified KYC requirements for the low-risk customers introduced by the Reserve Bank of Zimbabwe (RBZ) are another opportunity for inclusive finance in Zimbabwe. The sections of the population that are mainly excluded financially fall in the low-risk category and as such should not be subject to the stringent standard KYC requirement but should rather be given the benefit of simplified account opening requirements (Reserve Bank of Zimbabwe, 2016).

The financial literacy strategy of the Zimbabwe National Financial Inclusion Strategy 2016-2020 by the Reserve Bank of Zimbabwe is seen as an opportunity to address financial literacy deficiency (Reserve Bank of Zimbabwe, 2016). It is hoped that financial literacy will help consumers of financial products and services to acquire knowledge, skills, attitude, and behavior that promote awareness of financial opportunities thereby making well-informed decisions (Reserve Bank of Zimbabwe, 2016).

\section{Conclusion and Policy Recommendations}

Understanding the determinants, challenges, and opportunities of financial inclusion is very important if Zimbabwe is to achieve its goals and objectives of inclusive finance. In this paper, we use the most recent data that is obtained from the 2017 financial inclusion survey for Zimbabwe available on the World Bank's Findex Database. We find that $59 \%$ of the respondents have an account. However, only $32 \%$ of the respondents have an account with a financial institution. We also find that females are less likely to have an account compared to males. 
In addition, the probability of having an account increases with age, however, the marginal effect of age squared is negative implying that the elderly are less likely to own an account. The probability of being financially included is also found to increase with one's level of education and income level. Being employed also increases the likelihood that one will have an account. On the other hand, the expense/transaction cost of financial services, lack of trust/confidence in the financial system, and lack of documents such as national identity card reduce the probability of being financially included.

The major challenges to financial inclusion in Zimbabwe are identified as; financial illiteracy, lack of formal identification documents, lack of trust/confidence in the financial system, fragile economy, rural poor and gender inequality, and high transaction costs of financial services. Notwithstanding, mobile money services such as Eco-cash, Tel-cash, and One-money provide an opportunity for increasing financial inclusion in Zimbabwe. Additionally, the establishment of the women's Bank of Zimbabwe aimed at promoting Women's financial inclusion, the simplified KYC requirements for low-income groups and the financial inclusion strategy commission by the Reserve Bank of Zimbabwe are hoped to promote financial inclusion.

This paper recommends that to make finance inclusive, the Zimbabwean Government should develop policies that target marginalized groups such as the elderly, rural population, low-income earners, and females. The Government should also develop a strong consumer protection regulatory framework to restore confidence in the financial system. The Reserve Bank of Zimbabwe should encourage the use of accounts with the simplified KYC requirements to ease documentation requirements. Importantly, financial education strategies should be implemented to increase financial literacy. Moreover, the government should develop strategies that address the unemployment issue since employment increases the chances of financial inclusion. Furthermore, reducing the transaction costs of financial services could also improve financial inclusion.

\section{References}

Abel, S., Mutandwa, L., \& Roux, P. L. (2018). A review of determinants of financial inclusion. International Journal of Economics and Financial Issues, Econjournals, 8(3), 1-8.

Asuming, P. O., Osei-agyei, L. G., \& Ibrahim, J. (2019). Financial inclusion in Sub-Saharan Africa: Recent trends and determinants. Journal of African Business, 20(1), 112-134. https://doi.org/10.1080/15228916.2018.1484209

Babajide, A. A., Adegboye, F. B., \& Omankhanlen, A. E. (2015). Financial inclusion and economic growth in Nigeria. International Journal of Economics and Financial Issues, 5(3), 629-637.

Barugahara, F. (2012). Financial development and income inequality: Does inflation matter?.

Chitokwindo, S., Mago, S., \& Hofisi, C. (2014). Financial inclusion in Zimbabwe: A contextual overview. Mediterranean Journal of Social Sciences, 5(20), 415-423. https://doi.org/10.5901/mjss.2014.v5n20p415

Demirguc-Kunt, A., \& Klapper, L. (2012). Measuring Financial Inclusion: The global findex database. Policy Research Working Papers, 22 June 2013. https://doi.org/10.1596/1813-9450-6025

Demirguc-kunt, A., Klapper, L., Singer, D., Oudheusden, P. V., Guadamillas, M., Kendall, J., ... Pearce, D. (2014). Global findex database 2014: Measuring financial inclusion around the world. Retrieved from http://pubdocs.worldbank.org/en/681361466184854434/2014-Global-Findex-Report-DKSV.pdf

Efobi, U., Beecroft, I., \& Osabuohien, E. (2014). Access to and use of bank services in Nigeria: Micro-econometric evidence. Review of Development Finance, 4(2), 104-114. https://doi.org/10.1016/j.rdf.2014.05.002

Gujarati, D. (2006). Econometria básica (4th ed.). Elsevier.

Joshi, D. (2011). Financial inclusion as defined by rbi twin aspects of financial inclusion. Retrieved from https://www.oecd.org/finance/financial-education/48303408.pdf

Masiyandima, N., Mlambo, K., \& Nyarota, S. (2017). Financial inclusion and quality of livelihood. Retrieved from https://2017.essa.org.za>fullpaper>essa_3578

Munyanyi, W. (2014). Women financial inclusion in zimbabwe: a descriptive comparison of rural and urban populaces. International Journal of Education and Research, 2(6), 255-266.

NewsDay. (2015, July). SMEs contribute 40\% to GDP. Retrieved from www.newsday.co.zw

Park, C. Y., \& Mercado, R. V. (2015). Financial inclusion, poverty and income inequality in developing Asia. $A D B$ Economics Working Paper Series, (426), 17.

Reserve Bank of Zimbabwe. (2016). Zimbabwe national financial inclusion strategy: 2016-2020. 
Sharma, D. (2016). Nexus between financial inclusion and economic growth: Evidence from the emerging Indian economy. Journal of Financial Economic Policy, 8(1), 13-36.

The Zimbabwe National Budget Statement. (2016). Building a conducive environment that attracts foreign direct investment. https://doi.org/10.1016/j.enzmictec.2005.02.019

World Bank. (2012). Zimbabwe - FinScope MSME survey 2012. Washington, DC, USA. Retrieved from http://documents.worldbank.org/curated/en/780081468137402417/Zimbabwe-FinScope-MSME-survey-2012

Zimbabwe FinScope Consumer Survey. (2014). FinScope Consumer Survey Zimbabwe 2014.

Zimbabwe, R. B. (n.d.). Zimbabwe National financial Inclusion Strategy 2016-2020.

Zins, A., \& Weill, L. (2016). The determinants of financial inclusion in Africa. Review of Development Finance, 6(1), 46-57. https://doi.org/10.1016/j.rdf.2016.05.001

\section{Copyrights}

Copyright for this article is retained by the author(s), with first publication rights granted to the journal.

This is an open-access article distributed under the terms and conditions of the Creative Commons Attribution license (http://creativecommons.org/licenses/by/4.0/). 